\title{
CORRELAÇÃO ENTRE O PADRÃO DE EXPRESSÃO TECIDUAL E OS VALORES SÉRICOS DO ANTÍGENO CARCINOEMBRIONÁRIO EM DOENTES COM CÂNCER COLORRETAL
}

\author{
CARLOS AUGUSTO REAL MARTINEZ ${ }^{1}$, DENISE GONÇALVES PRIOLLI ${ }^{2}$, IZILDA APARECIDA CARDINALLI ${ }^{3}$, \\ HELENICE PIOVESAN ${ }^{3}$, JOSÉ AIRES PEREIRA ${ }^{3}$, JAQUES WAISBERG ${ }^{4}$, NELSON FONTANA MARGARIDO $^{5}$
}

${ }^{1}$ Programa de Pós-Graduação em Ciências da Saúde da Universidade São Francisco, ${ }^{2}$ Disciplina de Cirurgia Geral do Curso de Medicina da Universidade São Francisco, ${ }^{3}$ Disciplina de Anatomia Patológica do Curso de Medicina da Universidade São Francisco, ${ }^{4}$ Disciplina de Cirurgia do Aparelho Digestivo da Faculdade de Medicina do ABC, ${ }^{5}$ Disciplina de Técnica Cirúrgica da Faculdade de Medicina da Universidade de São Paulo.

MARTINEZ CAR , PRIOLLI DG, CARDINALLI IA, PIOVESAN H, PEREIRA JA, WAISBERG J, MARGARIDO NF. Correlação entre o Padrão de Expressão Tecidual e os Valores Séricos do Antígeno Carcinoembrionário em Doentes com Câncer Colorretal. Rev bras Coloproct, 2006;26(1):41-53.

RESUMO: A correlação entre diferentes padrões de expressão celular do CEA e a quantificação sérica do antígeno é assunto controvertido. Objetivo: O objetivo do presente estudo foi verificar se o padrão de distribuição tecidual do CEA no carcinoma colorretal, se correlaciona com seus níveis séricos. Método: Estudaram-se 24 pacientes portadores de adenocarcinoma colorretal, com média de idade de 62,6 anos. A mensuração sérica foi realizada por quimioluminescência. No estudo do padrão de distribuição tecidual empregou-se método imunoistoquímico com a técnica da estreptavidina-biotina peroxidase, utilizando anticorpos monoclonais anti-CEA. O padrão de expressão tecidual foi classificado em apical, citoplasmático e estromal, segundo a localização predominante do CEA. A intensidade da imunoexpressão foi classificada em leve, moderada e forte. Empregou-se o teste de Mann-Whitney na comparação dos níveis de CEA sérico, segundo o padrão de distribuição tecidual e o grau histológico do tumor, o teste de KruskalWallis para análise de variância e o teste de Spearman para avaliação da correlação entre as variáveis estudadas, adotando-se nível de significância de $5 \%$ (p<0,05). Resultados: Dois (8,3\%) doentes foram classificados no estádio A de Dukes, 12 (50,0\%) no B e 10 $\mathbf{( 4 1 , 6 \% ) ~ n o ~ C . ~ O s ~ v a l o r e s ~ m e ́ d i o s ~ d o ~ C E A ~ s e ́ r i c o ~ n o s ~ d o e n t e s ~ c o m ~ t u m o r e s ~ r e s t r i t o s ~ a ̀ ~ p a r e d e ~ i n t e s t i n a l ~ ( A ~ e ~ B ~ d e ~ D u k e s ) ~ f o r a m ~}$ significativamente menores que os dos doentes com comprometimento linfonodal $(p=0,0139)$. Nos $14(58,3 \%)$ enfermos com padrão apical de distribuição o valor médio de CEA sérico era de 4,0 ng/ml, enquanto nos 10 (41,6\%) em que havia expressão do tipo citoplasmática o valor médio do CEA sérico era de $31,0 \mathrm{ng} / \mathrm{ml}(\mathbf{p}=\mathbf{0 , 0 0 0 2})$. Independente da graduação histológica, tumores com expressão tecidual do tipo apical apresentavam valores séricos do CEA significativamente menores do que tumores com padrão citoplasmático $(\mathbf{p}<0.05)$ Não se encontrou padrão estromal de distribuição. Houve correlação estatisticamente significante entre o padrão de distribuição tecidual, valores séricos do CEA e a classificação de Dukes. Conclusão: Os resultados do presente estudo permitem concluir que tumores com padrão de distribuição tecidual citoplasmática cursam com valores séricos de CEA significativamente mais elevados que tumores com padrão de distribuição apical. Existe correlação positiva e estatisticamente significante, entre os diferentes padrões de distribuição celular do CEA, seus níveis séricos e o estadiamento da doença. Descritores: Neoplasias colorretais; Antígeno carcinoembrionário; Imunohistoquímica; Estadiamento de neoplasias.

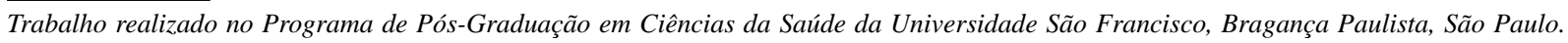

$\overline{\text { Recebido em 13/01/2006 }}$

Aceito para publicação em 16/02/2006 


\section{INTRODUÇÃO}

O antígeno carcinoembrionário (CEA) foi isolado pela primeira vez por Gold e Freedman em $1965^{1,2}$ no intestino de fetos e de doentes portadores de câncer colorretal. O CEA é uma imunoglobulina cuja principal função é promover a adesão molecular intercelular ${ }^{3,4}$. Pesquisas que utilizam técnicas imunoistoquímicas revelaram que o CEA é um antígeno habitualmente presente nas células da mucosa cólica normal e nas do carcinoma colorretal ${ }^{5,6}$. A principal diferença entre o conteúdo de CEA nas células normais e neoplásicas aparenta ser muito mais quantitativa do que qualitativa ${ }^{6}$. Contudo, estudos ultraestruturais demonstraram que existem diferenças no padrão de distribuição celular do CEA quando se compara o tecido normal com o neoplásico ${ }^{7}$.

Hamada e col. ${ }^{8}$, analisando por método imunoistoquímico doentes com adenocarcinoma colorretal, verificaram que o padrão de distribuição do CEA no tecido neoplásico ocorria de três formas distintas, classificando-as em três padrões principais: apical, citoplasmático e estromal. No padrão de distribuição apical, o CEA é encontrado junto à membrana citoplasmática na porção apical das células epiteliais cólicas voltadas para a luz glandular. No padrão citoplasmático, o antígeno é encontrado em ambos os pólos celulares e na porção basolateral das células da mucosa do cólon, distribuindo-se em mais de $30 \%$ do citoplasma celular. No padrão de distribuição estromal, além da coloração tecidual, o antígeno é demonstrado em mais de $30 \%$ do estroma vizinho. Esses autores sugeriram que os padrões de distribuição citoplasmática e estromal, pela maior proximidade com os vasos linfáticos e sangüíneos, permitiriam que o CEA atingisse com mais facilidade a circulação sistêmica e, portanto, estariam relacionados com níveis séricos do antígeno mais elevados quando comparados aos casos com distribuição apical ${ }^{8}$.

A identificação do CEA no tecido neoplásico por meio de método imunoistoquímico, e sua correlação com os valores séricos, tem sido estudada com finalidade de se encontrar a lógica biológica da relação entre a fonte de produção tecidual e seus níveis circulantes $^{8-12}$. Tais estudos pretenderam, na realidade, estabelecer a dinâmica capaz de explicar o potencial diagnóstico e, principalmente, o valor prognóstico dos níveis de CEA pré-operatórios encontrados no sangue 9 .
A correlação entre a fonte de produção tecidual, analisada por métodos imunoistoquímicos, e os níveis sangüíneos do CEA apresenta resultados controversos $^{10-13}$. Enquanto algumas pesquisas estabeleceram estreita correlação entre fonte de produção tecidual do CEA e seu nível sérico, em outras se verificou, até mesmo, a existência de pequena porcentagem de carcinomas colorretais, escassamente produtores de CEA, que evoluem com valores séricos normais, nos quais o seguimento dos doentes pela mensuração sangüínea do antígeno não seria útil na detecção de eventuais recidivas ${ }^{11-14}$

O objetivo do presente estudo foi avaliar, por meio de técnica imunoistoquímica, se o padrão de distribuição celular do CEA em doentes portadores de carcinoma colorretal, encontra-se correlacionado com o nível sérico do antígeno e o estadiamento da doença.

\section{MÉTODO}

A realização deste trabalho foi aprovada pelo Comitê de Ética em Pesquisa da Universidade São Francisco em Bragança Paulista, tendo todos os pacientes, após esclarecimento dos objetivos da pesquisa, assinado Termo de Consentimento concordando em participar espontaneamente do estudo.

\section{Casuística}

Foram estudados 24 doentes, com igual número entre homens e mulheres, portadores de carcinoma colorretal, operados com intenção curativa, no período de 2002 a 2003.

Utilizou-se o estadiamento de Dukes do carcinoma colorretal, classificando como pertencentes ao estádio $\mathrm{A}$, os tumores que se estendiam até a camada muscular externa da parede intestinal; como Dukes B, os que se estendiam por toda a parede intestinal comprometendo inclusive o tecido adiposo adjacente; e como C, quando havia comprometimento de linfonodos, independente do nível de penetração da neoplasia na parede intestinal.

As características clínicas e anatomo-patológicas dos doentes são mostradas na Tabela-1.

Consideraram-se como critério de exclusão os fumantes, a presença de carcinomatose peritoneal, portadores de doença hepática, e enfermos com metástases à distância. Todos os doentes tiveram o 
Tabela 1 - Características clínicas e anátomo-patológicas da casuística

\begin{tabular}{ll}
\hline Sexo & \\
Homens & $12 / 24$ \\
Mulheres & $12 / 24$ \\
& \\
Média de Idade (anos) & 57,2 anos \\
Homens & 68,0 anos \\
Mulheres & 62,6 anos \\
Geral & \\
& \\
Localização & $11 / 24(45.8 \%)$ \\
Sigmóide & $10 / 24(41.6 \%)$ \\
Reto & $2 / 24(8.3 \%)$ \\
Cólon Ascendente & $1 / 24(4.3 \%)$ \\
Cólon Transverso & \\
Estadiamento & \\
Dukes & \\
A & \\
B & $2 / 24(8.3 \%)$ \\
C & $12 / 24(50.0 \%)$ \\
Grau de diferenciação celular & $10 / 24(41.6 \%)$ \\
Bem diferenciado & \\
Moderadamente diferenciado & $14 / 24(58.3 \%)$ \\
Pouco diferenciado & $2 / 24(8.3 \%)$ \\
\hline
\end{tabular}

diagnóstico de adenocarcinoma colorretal confirmado por dois patologistas experientes.

\section{2 - Dosagem do Antígeno Carcinoembrionário}

Amostras de sangue foram colhidas na sala cirúrgica, antes do início da operação, por punção venosa no membro superior, e encaminhadas de forma imediata para a determinação do nível do CEA sangüíneo, por quimioluminescência, sendo o resultado expresso em nanogramas por mililitro (ng/ ml). A mensuração do CEA foi sempre realizada no mesmo laboratório pelo mesmo técnico, utilizando-se kit de um único fornecedor. Foram considerados como normais valores menores ou iguais a 5,0ng/ml.

\section{3 - Exame Anátomo-Patológico}

Inicialmente realizou-se o estudo macroscópico dos espécimes extirpados, analisando-se a loca- lização do tumor, aspecto macroscópico e tamanho. Em seguida para a realização do estudo histopatológico, todos os espécimes cirúrgicos, previamente fixados em solução de formol a $10 \%$, foram emblocados em parafina. Três cortes de $4 \mu \mathrm{m}$ na periferia do tumor para obtenção de áreas com e sem neoplasia, foram obtidos de cada bloco, sendo corados, inicialmente, pela técnica da hematoxilina-eosina para diagnóstico microscópico e avaliação do nível de invasão na parede, tipo histológico, grau de diferenciação celular e verificação da presença de linfonodos comprometidos pela neoplasia.

\section{4- Técnica Imunoistoquímica}

Todos os espécimes, fixados em formalina e emblocados em parafina, foram submetidos a três cortes adicionais de $4 \mu \mathrm{m}$, retirados da periferia do tumor e depositados em lâminas previamente identificadas. Inicialmente as lâminas foram desparafinadas por três banhos sucessivos de cinco minutos em xilol. Realizouse a reidratação, submergindo as lâminas em álcool absoluto a $95 \%, 80 \%$ e $50 \%$, seguida de lavagem por cinco minutos em água corrente e posteriormente em água destilada. As lâminas foram então acondicionadas em recipiente próprio e submersas em solução tampão de fosfato de sódio 0,05 $\mathrm{M}$ e $\mathrm{pH}$ 7,2 (PBS) por 10 minutos e depois secas com papel filtro. Foi realizado bloqueio das peroxidases endógenas pelo gotejamento de peróxido de hidrogênio $30 \mathrm{~V}$ a $3 \%$, em câmara úmida, à temperatura ambiente, durante 10 minutos, seguido de mais uma lavagem com PBS por 10 minutos. Terminadas estas etapas, realizou-se a recuperação antigênica na qual as lâminas foram acondicionadas em cuba com solução de citrato $10 \mathrm{mM}, \mathrm{pH}$ 6,0 e submetidas em microondas (potência alta) durante 15 minutos (três ciclos de cinco minutos cada, completando o recipiente com solução de citrato ao término de cada ciclo). Ao fim desse processo, foram deixadas esfriar por 20 minutos no interior do forno de microondas, seguido de nova lavagem com PBS por cinco minutos. O anticorpo primário monoclonal anti-CEA (Dako Cytomation ${ }^{\circledR}$, Copenhagen, Dinamarca- Clone II-7 $\mathrm{IgG1}$ ) foi diluído na proporção de 1:800 em soro albumina bovina (Sigma ${ }^{\circledR}$, Saint Louis, EUA). Todas as lâminas foram cobertas com cerca de $100 \mu \mathrm{L}$ dessa solução, mantidas por 30 minutos à temperatura ambiente e levadas para câmara úmida em refrigeração 
a $4^{\circ} \mathrm{C}$ por 24 horas. Após esse período de incubação, as lâminas foram novamente lavadas com PBS por cinco minutos, gotejadas com o anticorpo secundário (Dako Cytomation ${ }^{\circledR}$, Copenhagen, Dinamarca), na diluição de 1:160 em PBS, e reservadas em câmara úmida durante uma hora à temperatura ambiente. A seguir, realizou-se nova lavagem com PBS por cinco minutos e aplicou-se o complexo estreptavidina-biotina-peroxidase (Dako Cytomation ${ }^{\circledR}$, Copenhagen, Dinamarca) preparado no momento de sua utilização, na diluição de 1:100 em PBS, por 45 minutos. As lâminas foram reveladas, após nova lavagem com PBS por cinco minutos, usando-se cromógeno (tetrahidrocloridrato de diaminobenzidina DAB 10mg em $10 \mathrm{ml}$ de PBS + $3 \mathrm{ml}$ de água oxigenada), preparado cinco minutos antes de terminar o tempo de exposição ao complexo $\mathrm{ABC}$, gotejado e permanecendo sobre elas por três minutos. Completado este tempo, as lâminas foram lavadas em água corrente destilada por cinco minutos, contra-coradas com hematoxilina de Harris por 30 segundos, e novamente lavadas em água corrente destilada por cinco minutos para em seguida serem desidratadas, por submersão em etanol $50 \%, 80 \%$, $95 \%$ e absoluto e em xilol, duas vezes por um minuto cada. Finalmente as lâminas foram montadas, rotuladas e mantidas em posição horizontal por 24 horas. O controle da imunocoloração foi realizado com lâminas confeccionadas, com a mesma técnica, sem adição do anticorpo primário.

\section{5 - Leitura das Lâminas}

Para análise microscópica utilizou-se microscópio óptico comum, com magnificação final de 200 vezes. Considerou-se, como reação positiva, a coloração que ocorreu de modo difuso, com pontos de intensidade variáveis e distribuição homogênea. Todas as lâminas foram lidas por dois patologistas experientes sem conhecimento prévio das características clínicas de cada doente, e com acesso somente aos seus próprios resultados, os quais classificaram a expressão tecidual do CEA segundo duas variáveis: padrão de distribuição celular e intensidade de imunocoloração.

A leitura da imunocoloração foi sempre realizada na região de graduação histotológica (diferenciação celular) do tumor, definida previamente no estudo convencional pela técnica da hematoxilinaeosina. Assim, caso a neoplasia fosse considerada como bem diferenciada, a leitura do padrão e intensidade de expressão tecidual obtida pela imunoistoquímica seria realizada em uma área bem diferenciada. Adotou-se a classificação proposta por Hamada e col $1985^{8}$ para a definição do tipo de distribuição tecidual do CEA encontrado na imunocoloração (Figura-1).

A intensidade de expressão foi classificada em três graus após observação de três campos aleatórios, posicionados sobre áreas do tumor com a mesma graduação histológica: (1) leve $(+/+++)$, quando a coloração atingia até $30 \%$ das células; (2) moderada $(++/+++)$, quando a coloração estava presente de 30 a $70 \%$ das células; (3) forte $(+++/+++)$, quando mais de $70 \%$ das células apresentavam a imunocoloração. Adotou-se como valor individual para cada patologista a moda entre a leitura dos três campos e como valor final, a moda das leituras dos dois profissionais.

\section{6 - Estudo Estatístico}

Os dados obtidos com relação aos valores séricos do CEA foram estudados comparativamente pelos testes Mann-Whitney. Para análise de variância empregou-se o teste de Kruskal-Wallis. Aplicou-se o coeficiente de Spearman para verificar a existência de correlação significativa entre as variáveis estudadas, fixando-se em 5\% (p<0,05) o coeficiente para rejeição da hipótese de nulidade em todos os testes adotados.

\section{RESULTADOS}

Foi possível identificar a expressão imunoistoquímica tecidual do CEA nos 24 doentes estudados. Em todos, a intensidade de expressão tecidual variava de célula para célula e de glândula para glândula conforme o campo estudado; entretanto o mesmo padrão de localização era mantido na maior parte do tecido selecionado. Da mesma forma no tecido normal, de todos os casos estudados, o antígeno era identificado como uma tênue camada, localizada junto à membrana citoplasmática no pólo apical das células e na luz glandular (Figura 1-D).

O padrão de distribuição e a intensidade de expressão tecidual obtidos nos 24 enfermos estudados encontram-se relacionados na Tabela- 2 .

A Tabela-3 mostra a intensidade de expressão tecidual do CEA obtida na presente casuística para cada um dos padrões de distribuição tecidual encontrados. 


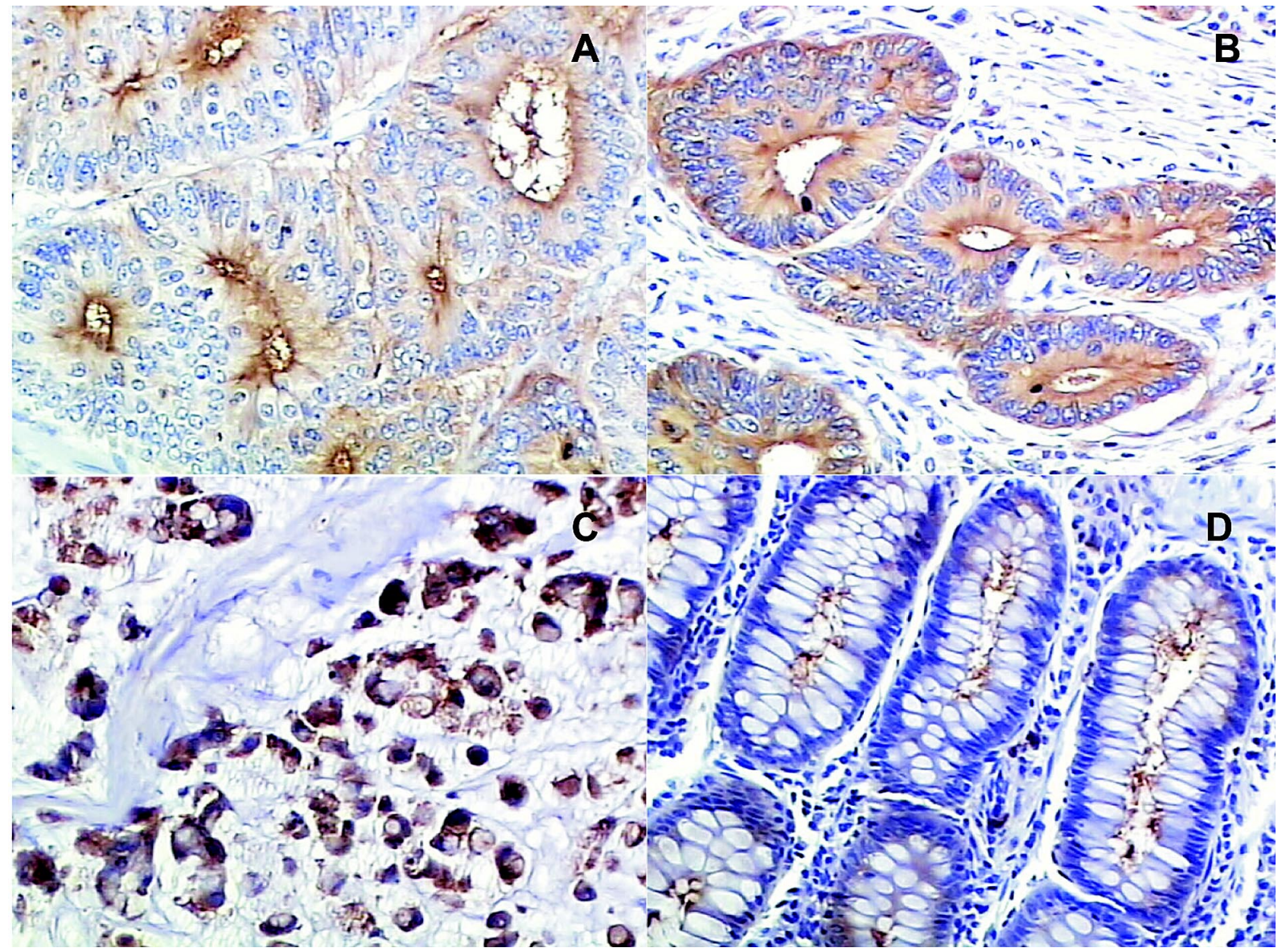

Figura 1 - Diferentes padrões imunoistoquímicos de distribuição tecidual do antígeno carcinoembrionário no carcinoma colorretal e no tecido normal, revelado pelo anticorpo monoclonal específico anti-CEA e contracorados pela Hematoxilina de Harris: A apical (200x); B citoplasmático (200x); C estromal (400x), e D na mucosa cólica normal (200x).

Tabela 2 - Padrão de distribuição tecidual e intensidade de expressão do CEA.

\begin{tabular}{lcc}
\hline & n & \% \\
\hline $\begin{array}{l}\text { Diagnóstico Patológico } \\
\text { Adenocarcinoma }\end{array}$ & 24 & 100 \\
& & \\
Padrão de distribuição tecidual para CEA & 24 & 100 \\
$\quad$ Apical & 14 & 58,3 \\
$\quad$ Citoplasmática & 10 & 41,7 \\
Estromal & - & - \\
& & \\
Intensidade de imunocoloração & & \\
$\quad$ Leve & 2 & 8,3 \\
$\quad$ Moderada & 17 & 70,8 \\
Forte & 5 & 20,8 \\
\hline
\end{tabular}

Tabela 3 - Imunocoloração positiva para o CEA tecidual segundo o padrão de distribuição tecidual e intensidade de expressão.

\begin{tabular}{lcc}
\hline Padrão de distribuição tecidual & $\mathbf{n}$ & $\mathbf{\%}$ \\
\hline Apical & $\mathbf{1 4}$ & $\mathbf{1 0 0}$ \\
Leve & 2 & 14,2 \\
Moderada & 10 & 71,6 \\
Forte & 2 & 14,2 \\
Citoplasmática & & \\
$\quad$ Leve & $\mathbf{1 0}$ & $\mathbf{1 0 0}$ \\
Moderada & - & - \\
Forte & 7 & 70,0 \\
Estromal & 3 & 30,0 \\
\hline
\end{tabular}


Os valores médios do CEA sérico não apresentavam diferenças significantes, quando se estudavam as variáveis: sexo $(\mathrm{p}=0,1571)$; localização do tumor no cólon ou reto $(\mathrm{p}=0,4642)$; tipo histológico mucoprodutor ou usual $(\mathrm{p}=0,2453)$; dimensões maiores ou menores que cinco centímetros $(\mathrm{p}=0,0725)$.

A Tabela-4 mostra os valores séricos do CEA nos diferentes padrões de imunoexpressão celular. Os valores séricos encontrados nos doentes com padrão apical de distribuição tecidual foram significativamente menores do que os valores dos doentes com padrão citoplasmático de distribuição celular $(p=0,0002)$. Enfermos com tumores restritos à parede cólica (Dukes A + B), apresentavam níveis séricos de CEA significativamente menores que os doentes classificados no estádio $\mathrm{C}$ de Dukes ( $\mathrm{p}=$ 0,0139). Os valores séricos do CEA apresentavam níveis mais elevados nos tumores pouco diferenciados, quando comparados aos tumores com menor graduação histológica, não havendo diferenças significantes quando se comparavam tumores bem diferenciados e moderadamente diferenciados $(\mathrm{p}=$ $0,5840)$.

Tabela 4 - Média dos valores séricos do CEA segundo o padrão de distribuição tecidual, classificação de Dukes e grau histológico da neoplasia.

\begin{tabular}{lcc}
\hline Variáveis & n & CEA (ng/ml) \\
\hline Padrão de distribuição tecidual & & \\
$\quad$ Apical & 14 & $4,01^{*}$ \\
Citoplasmático & 10 & 31,03 \\
Estromal & - & - \\
Classificação de Dukes & & \\
A & 2 & $2,90^{*}$ \\
B & 12 & $8,63^{*}$ \\
C & 10 & 25,72 \\
Grau histológico & & \\
Bem diferenciado & 8 & 14,21 \\
Moderadamente diferenciado & 14 & 13,38 \\
Pouco diferenciado & 2 & 32,75 \\
\hline
\end{tabular}

$* p<0,05$

$\S$ Teste de Mann-Whitney

Padrão de distribuição tecidual: *Apical<Citoplasmático

Classificação de Dukes: $* A+B<C$
Tabela 5 - Média dos valores séricos do CEA relacionando padrão de distribuição tecidual e o grau de diferenciação celular.

\section{Grau de diferenciação celular CEA ng/ml}

\begin{tabular}{lccc}
\hline & \multicolumn{2}{c}{ Bem } & \multicolumn{2}{c}{ Moderadamente } & Pouco \\
diferenciado & diferenciado & diferenciado \\
\hline Apical & $2,28^{*}$ & $2,61^{*}$ & 23,60 \\
Citoplasmático & 26,15 & 32,76 & 41,90 \\
Estromal & - & - & - \\
\hline
\end{tabular}

$\S$ Teste de Kruskal-Wallis

${ }^{*} p<0,05$

*Bem diferenciado: Apical < Citoplasmático

* Moderadamente diferenciado: Apical < Citoplasmático

A Tabela-5 mostra os valores séricos do CEA relacionados ao grau histológico da neoplasia e ao padrão de distribuição tecidual detectado pela imunoistoquímica. Nos tumores pouco diferenciados a média dos valores séricos do CEA encontrava-se mais elevada que nos tumores moderadamente ou bem diferenciados com o mesmo padrão de expressão tecidual. Os tumores com padrão de distribuição apical bem diferenciados apresentavam valores séricos de CEA semelhantes aos tumores moderadamente diferenciados com o mesmo padrão de distribuição tecidual $(\mathrm{p}=0,8772)$, porém menores quando comparados às neoplasias pouco diferenciadas. Os tumores com padrão de distribuição citoplasmática bem diferenciados apresentavam valores séricos do CEA menores que os tumores moderadamente diferenciados com o mesmo padrão de distribuição tecidual, sem contudo existir diferenças significantes. $(\mathrm{p}=0,8075)$. Os tumores com padrão citoplasmático bem e moderadamente diferenciado também cursavam com valores inferiores aos dos tumores pouco diferenciados. Constatou-se ainda que entre os tumores bem diferenciados, os enfermos com padrão de distribuição apical, apresentavam valores séricos do CEA significativamente menores que os doentes com padrão de distribuição citoplasmática $(\mathrm{p}=0,0209)$. Da mesma forma, nos tumores classificados como moderadamente diferenciados, os doentes com padrão de distribuição do tipo apical apresentavam valores séricos do CEA significativamente menores que os doentes com padrão 
Tabela 6-Média dos valores séricos do CEA relacionando padrão de distribuição tecidual e intensidade de expressão tecidual.

\section{CEA ng/ml}

Intensidade de expressão tecidual

\begin{tabular}{lccc}
\hline & Leve & Moderada & Forte \\
\hline Apical & 2,25 & $4,48^{*}$ & 3,45 \\
Citoplasmático & - & 37,87 & 15,06
\end{tabular}

Estromal

$\S$ Teste de Kruskal-Wallis

${ }^{*} p<0,05$

Intensidade de expressão - Moderada: *Apical < Citoplasmático

de distribuição tecidual citoplasmática $(\mathrm{p}=0,0041)$. $\mathrm{O}$ doente com tumor pouco diferenciado com padrão de distribuição tecidual do tipo apical apresentava valor sérico do CEA inferior ao doente com padrão de distribuição citoplasmática.

A Tabela-6 mostra os valores médios do CEA sérico nos diferentes padrões de distribuição celular, segundo a intensidade de expressão tecidual do CEA. Verificou-se que os doentes com padrão de distribuição apical e intensidade de expressão moderada apresentavam níveis séricos do CEA significativamente menores que os doentes com padrão de distribuição do tipo citoplasmática $(\mathrm{p}=0,0025)$. Os pacientes com padrão de distribuição apical e intensidade de expressão forte também apresentavam valores de CEA inferiores aos doentes com padrão citoplasmático.

O estudo de correlação entre as múltiplas variáveis estudadas (Teste de Spearman) mostrou correlação positiva e significante entre o padrão de distribuição tecidual do CEA e os níveis séricos do CEA ( $r s=0,7694, p=0,0001$ ), entre padrão de distribuição tecidual do CEA e a classificação de Dukes ( $\mathrm{rs}=0,5555$, $\mathrm{p}=0,0048)$ e, entre os níveis séricos do CEA e a classificação de Dukes ( $r s=0,5342, p=0,0072)$.

\section{DISCUSSÃO}

Nos Estados Unidos, o câncer colorretal representa a segunda causa mais comum de morte por neoplasia entre os homens e a terceira entre as mulheres ${ }^{15}$. No Brasil, ocupa o terceiro posto como causa mais comum de morte relacionada ao câncer e sua incidência vem aumentando em comparação a outros tipos de tumores que acometem o aparelho digestivo $^{16}$. Apresenta maior incidência entre 50 e 70 anos de idade, podendo em 2 a $6 \%$ dos casos acometer a população mais jovem ${ }^{16,17}$. Com o aumento da expectativa de vida a neoplasia colorretal vem ganhando importância crescente no perfil da mortalidade por câncer em todo o mundo ${ }^{15,16}$.

O prognóstico da enfermidade encontra-se diretamente relacionado ao conhecimento do maior número de variáveis que possam identificar, com segurança, o risco do desenvolvimento de metástases. Dentre elas, a presença de células neoplásicas viáveis na corrente sangüínea é condição indispensável para a disseminação da doença ${ }^{17}$. O CEA é um antígeno presente na maioria das células neoplásicas dos doentes com câncer colorretal e sua presença em níveis elevados na corrente sangüínea, durante o seguimento pósoperatório, pode sugerir a existência de células neoplásicas viáveis produtoras do antígeno ${ }^{1}$. Assim sendo, o conhecimento detalhado da relação existente entre a fonte de produção tecidual do CEA e a dinâmica com que o antígeno atinge a corrente sangüínea, são aspectos importantes para melhor compreensão da evolução do câncer colorretal.

O CEA é formado por um conjunto de glicoproteínas semelhantes, pertencentes à família das imunoglobulinas, com peso molecular de $200 \mathrm{kDa}$, cuja principal função é promover a adesão intercelular ${ }^{4,5,18}$. Trata-se de glicoproteína produzida por tumores originários do tecido endodérmico, em especial os da mucosa do cólon, que possui determinantes antigênicos localizados na fração protéica da molécula formada por cadeias polipeptídicas simples, sendo o componente carboidrato composto principalmente por frutose, manose, galactose, $\mathrm{N}$-acetilglucosamina e $\mathrm{N}$ acetil-galactosamina ${ }^{4,6,19-22}$.

As células da mucosa cólica sintetizam o CEA de maneira contínua a partir de suas porções basais. Em virtude de uma orientação de migração polarizada, característica das células epiteliais especializadas, o antígeno atravessa o citoplasma através das cisternas de Golgi associando-se à membrana citoplasmática na região apical da célula, para a partir daí ser em parte eliminado para a luz intestinal ${ }^{7,8}$. Nas células 
neoplásicas do câncer colorretal existe perda da orientação de migração polarizada, ocorrendo com isso inversão do padrão de distribuição do antígeno no citoplasma celular. O fenômeno da perda de migração polarizada fica mais evidente à medida que a célula neoplásica se torna cada vez menos diferenciada ${ }^{7}$. A incapacidade de eliminar o CEA para luz intestinal, decorrente do fenômeno de inversão de migração polarizada, acarreta maior concentração do antígeno no interior da célula, facilitando sua difusão para o estroma tecidual e conseqüentemente para circulação sistêmica. Acredita-se que o fenômeno da inversão de migração polarizada, por facilitar a passagem do CEA para a corrente sangüínea seja uma das explicações plausíveis para valores séricos do antígeno, mais elevados nos portadores de carcinoma colorretal ${ }^{8}$.

A possibilidade de detecção do CEA no sangue por técnicas de radioimunoensaio, quimioluminescência e, mais recentemente, por técnica imunoenzimática com boa sensibilidade, permitiu que a mensuração sérica do antígeno passasse a ser utilizada de forma rotineira no acompanhamento de doentes portadores de câncer colorretal. Dessa maneira, haveria a possibilidade de se estabelecer uma correlação entre a fonte de produção tecidual e o nível sérico do CEA.

A mensuração sérica do CEA vem sendo utilizada com vários propósitos. Por apresentar baixa especificidade, já que pode encontrar-se elevado em diversas condições benignas, o CEA não é empregado como método diagnóstico. A dosagem do antígeno possui importante papel no acompanhamento pósoperatório dos enfermos portadores de câncer colorretal, podendo ao elevar-se ser indicador do surgimento de recidivas ${ }^{23}$. A manutenção de valores sangüíneos elevados após a extirpação do tumor pode ser indicativa de ressecção cirúrgica incompleta ${ }^{24}$. Ainda existem controvérsias quanto ao valor da mensuração pré-operatória do CEA como variável de importância prognóstica, principalmente nos estádios iniciais da doença ${ }^{24,25}$. A presença do CEA nas fezes torna atraente a possibilidade de que sua quantificação fecal possa vir a ser utilizada como método de rastreamento do câncer colorretal ${ }^{26,27}$.

A diferença no conteúdo de CEA entre células normais e neoplásicas parece ser muito mais quantitativa do que qualitativa e sua expressão imunoistoquímica tecidual pode sofrer variações dependendo do método de análise empregado ${ }^{8}$. No estudo do carcinoma colorretal em espécimes congelados, a detecção imunoistoquímica do CEA pode atingir até $100 \%$ das células da mucosa do intestino grosso ${ }^{9}$. De outro modo, quando a mensuração é feita em tecidos previamente fixados, o CEA é identificado em aproximadamente $60 \%$ das células neoplásicas e em apenas $14 \%$ das células normais ${ }^{28}$. A especificidade do anticorpo primário anti-CEA, empregado na técnica imunoistoquímica, é outra variável relacionada à maior capacidade de identificação do CEA nos tecidos ${ }^{29}$. Ao considerar-se os 24 doentes avaliados no presente estudo, apesar de empregar-se material fixado, pôdese identificar a presença do CEA em todos, tanto no tecido normal quanto no neoplásico, sugerindo que a dificuldade na identificação do antígeno no material fixado possa estar relacionada com a técnica imunoistoquímica empregada.

Em todos os enfermos foi possível observar diferenças tanto no padrão de distribuição tecidual quanto na intensidade de expressão do antígeno, quando se comparava tecido normal com neoplásico. Na mucosa cólica normal o CEA era identificado no pólo apical da célula junto à membrana citoplasmática e no interior da luz glandular, geralmente como uma tênue camada, de coloração acastanhada e com intensidade de expressão classificada como leve (Figura 1-D). Este padrão de distribuição identificado no tecido normal, bem como a leve intensidade de expressão, parece reforçar as evidências de que na célula normal existe uma produção tecidual limitada com orientação de polaridade definida no sentido da luz intestinal.

Nos portadores de câncer colorretal identificaram-se dois padrões principais de distribuição tecidual do CEA: apical e citoplasmático. Encontrouse o padrão apical de distribuição em 58,3\% (14/24) e o citoplasmático em 41,7\% (10/24) dos enfermos (Figura 1A e B), não se observando padrão de distribuição do tipo estromal. Este fato provavelmente se deva ao pequeno número de casos estudados e à dificuldade em se diferenciar o padrão estromal de distribuição do CEA, da coloração de células neoplásicas que invadiam o estroma tecidual (Figura 1C). Nas regiões onde existia grande infiltração da membrana basal por células neoplásicas ou necrose tecidual, havia áreas restritas onde talvez o padrão de expressão tecidual estromal pudesse ser considerado, entretanto o padrão de distribuição tecidual adotado 
para a leitura imunoistoquímica foi aquele encontrado nas áreas definidas previamente pela coloração convencional. A dificuldade em se diferenciar os principais padrões de distribuição tecidual do CEA, vem fazendo com que sejam propostas diversas classificações que adotam critérios de expressão diferentes, tanto na distribuição quanto na intensidade de expressão. Esta falta de uniformidade causa muita confusão na interpretação dos resultados descritos nos mais diferentes estudos ${ }^{12,13,29}$.

A pesquisa rotineira do padrão de expressão tecidual do CEA tem sido preconizada, pois permitiria aumentar a eficiência da mensuração sangüínea do antígeno como fator prognóstico nos doentes portadores de câncer colorretal ${ }^{12,13}$. No presente estudo, verificou-se que doentes com padrão de distribuição tecidual do tipo apical, apresentavam níveis séricos de CEA significativamente menores que os pacientes com padrão de distribuição citoplasmática $(\mathrm{p}=0,0002)$. Os doentes com padrão de distribuição apical apresentavam níveis médios de CEA sérico de 4,01 ng/ $\mathrm{ml}$ o que é concordante com os resultados de outros autores que encontraram valores inferiores a $10 \mathrm{ng} /$ $\mathrm{ml}^{8,30}$. Da mesma forma, doentes com padrão citoplasmático de distribuição do CEA apresentavam valores séricos médios de 31,00 ng/ml, resultado semelhante aos de pesquisas que encontraram valores maiores do que $10 \mathrm{ng} / \mathrm{ml}^{8,12,30}$.

Ao estudar-se a intensidade de expressão tecidual do CEA nas áreas neoplásicas, verificou-se que dos 14 doentes que apresentavam padrão de distribuição apical, dois mostravam intensidade de expressão leve 10, intensidade moderada e dois, forte. Cabe destacar que, apesar do padrão de distribuição tecidual apical assemelhar-se ao do tecido normal, nos 14 enfermos a intensidade de expressão tecidual detectada era nitidamente mais intensa quando comparada à do tecido normal, sugerindo maior capacidade de produção do CEA pela célula neoplásica (Figura 1 A). Nos 10 doentes com padrão citoplasmático, não houve intensidade de expressão leve, existindo sete com intensidade moderada e três, forte. Estes achados sugerem que a maior intensidade de expressão tecidual do CEA no padrão citoplasmático de distribuição talvez esteja relacionada não só à maior capacidade de produção do antígeno pela célula neoplásica, mas também ao maior acúmulo citoplasmático decorrente da menor capacidade da célula cancerosa em eliminar o antígeno para a luz intestinal (inversão da polaridade).

O padrão apical de distribuição tecidual do CEA em doentes com câncer colorretal vem sendo relacionado a menores níveis de CEA sérico e portal, quando comparado aos padrões de distribuição citoplasmática e estromal ${ }^{28,30-32}$. Os resultados da presente casuística parecem confirmar estas suspeitas. Dos 14 doentes com câncer colorretal cujo padrão de distribuição tecidual do CEA foi classificado como apical, 12 apresentavam intensidade de expressão moderada ou forte e, mesmo assim, os níveis séricos de CEA foram menores quando comparados àqueles dos doentes com padrão citoplasmático que apresentavam a mesma intensidade de expressão ( $\mathrm{p}=$ 0,0008). É possível que os menores níveis de CEA sérico nos doentes com padrão de distribuição do tipo apical ocorresse, pois apesar de existir importante concentração tecidual do CEA no pólo apical da célula, a maior parte do antígeno estaria sendo eliminada para a luz intestinal, resultando em menor contingente drenado para a circulação sangüínea. Estes achados sugerem que o padrão de distribuição tecidual na célula neoplásica possa estar tão relacionado à presença do CEA no sangue e nas fezes, quanto à própria capacidade de produção tecidual. Pesquisas que relacionem o conteúdo sérico e fecal do CEA em indivíduos sadios e em portadores de câncer colorretal com diferentes padrões de distribuição tecidual ainda merecem ser realizadas.

Já se demonstrou que a maior concentração do CEA no citoplasma celular e no estroma tecidual do carcinoma colorretal, em virtude de atingir com maior facilidade a circulação sistêmica, geralmente é acompanhada de valores séricos mais elevados ${ }^{8,30}$. Sete dos 10 enfermos com padrão de distribuição tecidual citoplasmática apresentavam intensidade de expressão classificada como moderada e em três ela era forte. Verificou-se que esses, doentes apresentavam valores médios de CEA sérico significativamente mais elevados que os doentes com distribuição do tipo apical com a mesma intensidade de expressão $(\mathrm{p}=0,0005)$, reforçando a idéia de que o padrão de distribuição tecidual encontra-se mais relacionado a valores elevados de CEA sérico do que a intensidade de produção. No momento estamos iniciando estudo com maior número de casos em que a quantificação do CEA tecidual está sendo mensurada por meio de método morfométrico computadorizado e através de 
espectrometria de massa. O objetivo desse estudo é verificar, de forma mais precisa, se os níveis séricos do CEA encontram-se mais relacionados à capacidade produtora da célula neoplásica ou à dificuldade em secretar o antígeno para a luz intestinal devido ao fenômeno de inversão da polaridade de migração.

Existem dúvidas se o padrão de distribuição tecidual e os níveis séricos do CEA nos doentes portadores de carcinoma colorretal também possam estar relacionados ao grau histológico do tumor (diferenciação celular) ${ }^{8,9,28}$. Evidenciou-se que a maioria dos doentes portadores de tumores bem diferenciados e com padrão de distribuição do tipo apical cursava com níveis séricos baixos de CEA. Por outro lado, portadores de tumores moderadamente ou pouco diferenciados e de padrão citoplasmático ou estromal cursavam com níveis séricos elevados. Entretanto, já se demonstrou que à medida que a neoplasia torna-se cada vez mais indiferenciada, pelo distanciamento progressivo da célula normal especializada, perderia a capacidade de produção tecidual do $\mathrm{CEA}^{7,14,33}$. Dessa forma, nos tumores indiferenciados poderia ocorrer uma menor produção tecidual do CEA, fazendo com que sua mensuração sérica possuísse menor importância no seguimento pósoperatório $^{14}$.

Na presente casuística, quando se compararam os valores séricos do CEA, nos diferentes graus de diferenciação do tumor, verificou-se que não havia diferença significante entre os doentes portadores de tumores bem ou moderadamente diferenciados $(\mathrm{p}=$ 0,5849). Apesar de dois doentes portadores de tumores pouco diferenciados apresentarem em média valores séricos do CEA mais elevados que os doentes com tumores bem ou moderadamente diferenciados, em virtude do tamanho da amostra o estudo comparativo ficou prejudicado. Ao se estudar o grau histológico do tumor e o padrão de distribuição tecidual do CEA, relacionando-os com a média dos níveis séricos do antígeno, verificou-se que, dos oito doentes com tumores bem diferenciados, quatro apresentavam distribuição do tipo apical e quatro, citoplasmática. Comparando-se os valores séricos do CEA nesses doentes observou-se que os doentes com tumores bem diferenciados com padrão de distribuição apical apresentavam valores séricos significativamente menores que os doentes com padrão citoplasmático $(\mathrm{p}=0,0209)$. Dos 14 doentes portadores de tumores moderadamente diferenciados, nove apresentavam padrão de distribuição do tipo apical e cinco, citoplasmática. Comparando-se os valores séricos do CEA nesses doentes constatou-se que os doentes com tumores moderadamente diferenciados com padrão de distribuição apical apresentavam valores séricos significativamente menores que os doentes com padrão citoplasmático $(\mathrm{p}=0,0041)$. Dos dois doentes com tumores pouco diferenciados, um apresentava padrão apical de distribuição tecidual e outro citoplasmático. O doente com padrão apical apresentava valor sérico do CEA menor que o doente com padrão citoplasmático.

Ao se estudar o padrão de distribuição tecidual do CEA e o grau histológico do tumor, relacionandoos com os níveis séricos do antígeno, verificou-se que dos 14 doentes com distribuição apical, quatro apresentavam neoplasia bem, nove moderadamente e um pouco diferenciada. Ao se analisar os valores do CEA sérico nestes doentes constatou-se, apesar de se tratar de um único caso, que o doente com neoplasia pouco diferenciada apresentava níveis séricos bem mais elevados em relação àqueles que possuíam tumores moderadamente ou bem diferenciados. Os enfermos com padrão de distribuição apical, portadores de tumores bem diferenciados apresentavam em média valores séricos de CEA semelhantes aos doentes com padrão apical e portadores de tumores moderadamente diferenciados $(\mathrm{p}=0,7383)$.

Dos 10 pacientes com padrão de distribuição tecidual do tipo citoplasmática, quatro eram portadores de tumores bem diferenciados, cinco moderadamente, e apenas um pouco diferenciado. Doentes com padrão de expressão tecidual do tipo citoplasmática e portadores de tumores bem diferenciados apresentavam em média valores séricos do CEA menores quando comparados àqueles portadores de tumores moderadamente diferenciados, sem contudo existirem diferenças significantes $(\mathrm{p}=0,8065)$. $\mathrm{O}$ único doente com carcinoma pouco diferenciado e com padrão de expressão tecidual citoplasmático apresentava nível de CEA sérico bem mais elevado, quando comparado ao dos doentes com tumores bem ou moderadamente diferenciados; todavia, como se tratava de um único enfermo, a avaliação fica comprometida.

A importância do padrão de distribuição tecidual nos valores séricos do CEA ficou evidente quando se constatou que, independente do grau histológico da neoplasia, foi possível demonstrar nos doentes com expressão tecidual do tipo apical, valores médios do CEA sérico, significativamente menores do que os valores 
dos doentes com expressão tecidual de padrão citoplasmático. Estes resultados sugerem que o padrão de expressão tecidual possa influir de maneira até mesmo mais importante que o grau histológico da neoplasia nos valores sangüíneos do CEA. Contudo, é importante destacar que grau de diferenciação celular do câncer colorretal é definido como o grau dominante na lâmina estudada, cabendo lembrar que em um mesmo tumor é possível encontrarem-se áreas bem, moderadamente e até mesmo pouco diferenciadas. Com o intuito de tentar padronizar a leitura e estabelecer uma relação mais real entre os valores séricos encontrados com o padrão imunoistoquímico de distribuição tecidual do CEA, o local selecionado para interpretação da lâmina foi aquele com a graduação histológica previamente definida pela técnica histológica convencional. Estudos relacionando os diferentes padrões de expressão tecidual de um mesmo tumor com os valores séricos do CEA ainda merecem ser realizados, com objetivo de verificar se os níveis sangüíneos do antígeno são determinados pelo grau histológico mais prevalente ou pelo maior grau encontrado. Da mesma forma, pesquisas relacionando o conteúdo sérico e fecal do CEA em indivíduos sadios e em portadores de câncer colorretal com diferentes graduações histológicas, ainda merecem ser realizadas com o objetivo de verificar se tumores com mesma graduação histológica, mas com padrões de distribuição distintos, apresentam diferenças nos níveis séricos e fecais do CEA.

O estádio anátomo-patológico do tumor também vem sendo relacionado com os níveis séricos do CEA, pois à medida que a neoplasia invade progressivamente a parede cólica, o acesso do antígeno à corrente sangüínea encontra-se facilitado devido a infiltração venosa e linfática ${ }^{34,35}$. Quanto mais avançado o estádio da classificação de Dukes, maiores são os valores encontrados do CEA sérico ${ }^{30}$. Já se demonstrou que neoplasias com estádios mais avançados da classificação de Dukes estão mais comumente associadas aos padrões citoplasmático e estromal de distribuição tecidual e a valores de CEA sérico elevados $8,12,35$. Tokunaga e col. ${ }^{35}$, estudando 49 portadores de carcinoma colorretal, nos quais a neoplasia invadia a camada submucosa da parede cólica, verificaram que o comprometimento linfonodal não ocorria em doentes com padrão de expressão do tipo ápico-luminal, ocorrendo, contudo, em 11,6\% dos tumores com padrão de distribuição citoplasmático e em $16,7 \%$ dos estromais. Os resultados obtidos no presente estudo parecem estar de acordo com esses achados. Dois dos 24 doentes em que a neoplasia foi estagiada como A da classificação de Dukes, apresentavam valores médios de CEA sérico de 2,90 ng/ml, já os classificados como B e C apresentavam em média valores de 13,43 ng/ml e 32,60 $\mathrm{ng} / \mathrm{ml}$, respectivamente. Quando se compararam os níveis séricos do CEA em doentes com tumores restritos à parede cólica (estádios A e B de Dukes), com àqueles em que já existia comprometimento linfonodal, verificouse que os valores séricos do antígeno eram significativamente menores nos enfermos com doença restrita à parede cólica $(\mathrm{p}=0,0139)$. Estes resultados sugerem que o grau de penetração do tumor na parede intestinal, além da quantidade de massa produtora do antígeno e da presença de tecido produtor de CEA fora da parede cólica, também possa estar relacionado aos níveis séricos do antígeno. Cabe destacar que não foi possível demonstrar-se diferenças significantes $(p=$ 0,0725 ) quando se comparavam tumores maiores ou menores que cinco centímetros, talvez devido ao tamanho da amostra.

Os valores séricos do CEA podem sofrer influência de múltiplas variáveis e dentre as analisadas, foi possível encontrar-se correlação positiva e significante, entre o padrão de expressão imunoistoquímica tecidual do CEA, seus níveis séricos e o estádio da doença segundo a classificação de Dukes.

Os resultados iniciais do presente estudo, apesar do pequeno número de doentes avaliados, sugerem que os diferentes padrões de distribuição tecidual encontramse relacionados aos níveis sangüíneos pré-operatórios do CEA, ao estadiamento anátomo-patológico e, indiretamente, ao prognóstico da doença. A determinação das características de distribuição tecidual do CEA pode dessa maneira, incrementar a importância da dosagem sérica do antígeno como fator prognóstico nos doentes portadores de carcinoma colorretal. Estudos com maior número de enfermos e com maior tempo de seguimento pós-operatório devem ser empreendidos, com o intuito de verificar se o padrão de distribuição tissular do CEA pode ser considerado como variável independente no prognóstico dos doentes portadores de câncer colorretal.

\section{CONCLUSÃO}

Considerando a metodologia empregada, os resultados do presente estudo permitem concluir que 
tumores com padrão citoplasmático de distribuição tecidual do CEA apresentam valores séricos do antígeno significativamente mais elevados que os tumores com padrão de distribuição apical, e que existe correlação positiva, e estatisticamente significante, entre os diferentes padrões de distribuição celular do CEA, seus níveis séricos e estadiamento da doença segundo a classificação de Dukes.

SUMMARY: The correlation between different cell expression patterns of CEA and the quantities of this antigen in serum is still a controversial subject. Objective - The objective of the present study was to verify whether there is a correlation between the distribution pattern of CEA in the neoplastic tissue and CEA levels in serum. Method - Twenty-four patients with colorectal cancer were studied. Their mean age was 62.6 years. The measurement of CEA in serum was done by quimioluminiscence technique. To study the tissue expression pattern, the immunohistochemical method with the streptavidin-biotin peroxidase technique was utilized with the use of anti-CEA monoclonal antibodies. The tissue expression pattern was classified as apical, cytoplasmic or stromal, according to the predominant localization of the CEA distribution in the neoplastic tissue. The intensity of the immunoexpression of CEA in the neoplastic tissue was classified as slight, moderate or strong. The Mann-Whitney test was used to compare the CEA levels in serum with the tissue distribution pattern and histological tumor grade. The Kruskal-Wallis test was used to variance analysis and Spearman test was used to analyze the correlation among the studied variables. The significance level of $5 \%(p<0.05)$ was adopted. Results - Two patients $(\mathbf{8 . 3 \%})$ were classified in Dukes stage A, $12(50.0 \%)$ in B and $10(41.6 \%)$ in $\mathrm{C}$. The mean CEA values in serum in patients with tumors restricted to the intestinal wall (Dukes A + B) were significantly lower than did the tumors with lymph node involvement $(\mathrm{p}=\mathbf{0 . 0 1 3 9})$. In the 14 patients $(\mathbf{5 8 . 3 \%})$ who presented an apical tissue expression pattern, the mean CEA value in serum was $4.0 \mathrm{ng} / \mathrm{ml}$, while in the 10 patients $(41.6 \%)$ with expression of cytoplasmic type, the mean CEA value in serum was $31.0 \mathrm{ng} / \mathrm{ml}(\mathrm{p}=\mathbf{0 . 0 0 0 2})$. Independent of the histological grade, the tumors with tissue expression of apical type presented CEA values in serum that were significantly lower than did the tumors with the cytoplasmic pattern $(p<0.05)$. No patients were found to have the stromal pattern of CEA distribution. There was a statistically significant correlation between the tissue expression pattern, CEA values in serum and the Dukes classification. Conclusion - The results from the present study allow concluding that tumors with the cytoplasmic pattern of CEA distribution presented serum values of the antigen significantly higher than apical pattern. There is a positive and statistically significant correlation between the different cell distribution patterns of CEA, its levels in serum and the staging of the disease.

Key words: Colorectal neoplasm; Carcinoembryonic antigen; Immunohistochemistry; Neoplasm staging.

\section{REFERÊNCIAS BIBLIOGRÁFICAS}

1. Gold P, Freedman SO. Demonstration of tumor-specific antigens in human carcinoma by immunological tolerance and absorption techniques. J Exp Med. 1965; 121:439-42.

2. Gold P, Freedman SO. Specific carcinoembryonic antigens of the human digestive system. J Exp Med. 1965; 122:467-81.

3. Paxton RJ, Mooser G, Pande H, Lee TD, Shively JE. Sequence analyses of carcinoembryonic antigen: identification of glycosylation sites and homology with the immunoglobulin supergene family. Proc Nat Acad Sci. 1987; 84:920-24.

4. Benchimol S, Fuks A, Joty S, Beauchemin N, Shirota K, Stanners CP. Carcinoembryonic antigen: a human tumor marker, function as an intercellular adhesion molecule. Cell. 1989; 57: 327-34.

5. Wagener C, Csaszar H, Totovic V, Breuer H. A highly sensitive method for the demonstration of carcinoembryonic antigen in normal and neoplastic colonic tissue. Histochemistry. 1978; 58:1-11.

6. Fritsche R, Mach JP. Isolation and characterization of carcinoembryonic antigen (CEA) extracted from normal human colon mucosa. Immunochemistry. 1977; 14:119-27.
7. Ahnen DJ, Nakane PK, Brown WR. Ultra structural localization of carcinoembryonic antigen in normal and colon cancer. Abnormal distribution of CEA on the surface of colon cancer cells. Cancer. 1982; 49: 2077-90.

8. Hamada Y, Yamamura M, Hioki K, Yamamoto M, Nagura H, Watanabe K. Immunohistochemical study of carcinoembryonic antigen in patients with colorectal cancer. Correlation with plasma carcinoembryonic antigen levels. Cancer. 1985; 55: 136-41.

9. Huitric E, Laumoniec R, Burtin P, Von Kleist S, Chavonel G. An optical and ultrastructural study of the localization of carcinoembryonic antigen (CEA) in normal and cancerous human retocolonic mucosa. Lab Invest. 1976; 34: 97-107.

10. Burtin P, Von Cleist S, King M. Immunohistological localization of CEA and nonspecific cross-reacting antigen in gastrointestinal normal and tumoral tissues. Cancer Res. 1973; 33: 3299-305.

11. Page M, Dalifard I, Bertrand G, Bocquillon PG, Daver A. Immunostaining of colorectal cancer with monoclonal antiCEA antibodies compared to serum and tumor CEA content Anticancer Res. 1986; 6: 893-6.

12. Chiquillo Barber MT, Bort Martí J, Navarro Fos S. Pérez 
Bacete M, Esclápez Valero J, Gomez-Ferrer Bayo F. A correlation between serum levels of preoperative CEA and CEA immunohistochemical staining in colorectal carcinoma. Rev Esp Enferm Dig. 1993; 83:249-54.

13. Chiquillo Barber MT, Navarro Fos S, Perez Bacete M, Esclapez Valero JP, Gomes-Ferrer Bayo F, Bort Marti J. The determination of tissue CEA in colorectal adenocarcinoma: an immunohistochemical study. Rev Esp Enferm Dig.1993; 83:241-7.

14. Goslin RH, O’Brien MJ, Steele G, Mayer R, Wilson R, Corson JM, Zamcheck N. Correlation of plasma CEA and CEA tissue staining in poorly differentiated colorectal cancer. Am J Med. 1981; 71:246-53.

15. Boring CC, Squires TS, Tong T. Cancer statistics 1993. CA Cancer J Clin. 1993; 43:7-26.

16. Neves FJ, Mattos IE, Koifman RJ. Mortalidade por câncer de cólon e reto nas capitais brasileiras no período 1980-1997. Arq Gastroenterol. 2005; 42:63-70.

17. Fidler IJ. Critical factors in the biology of human cancer metastasis: twenty-eighth G.H.A. Clowes memorial award lecture. Cancer Res. 1990; 50:6130-8.

18. Moore TL, Kupchinick HZ, Marcon N, Zamcheck N. Carcinoembryonic antigen assay in cancer of the colon and pancreas and other digestive tract disorders. Am J Dig Dis. 1971; 16:1-7.

19. Reynoso G, Chu TM, Holyoke D, Cohen E, Nemoto T, Wang JJ, Chuang Y, Guinan P, Murphy GP. Carcinoembryonic antigen in patients with different cancers. J Am Med Ass. 1972; 220:361-5.

20. Pritchard DG, Todd CW. The chemistry of carcinoembryonic antigen. In: Heberman RB \& McIntere KR. Immunodiagnosis of cancer. New York, Marcel Dekker, 1979; 1:165-81.

21. Schoentag R, Williams V, Kuhns W. The distribution of blood group substance and CEA in colorectal carcinoma. Cancer. 1984; 53:503-509.

22. Cutait R, Borges JLA, Cutait DE. Aplicações clínicas do antígeno carcinoembrionário em câncer colorretal. Rev bras Coloproct. 1988; 8:28-33.

23. Bromberg SH, Waisberg J, Pradal MG, Menezes AM, Assis LA, Ferrão SOT, Barreto E, Godoy AC. Níveis do antígeno carcinoembriônico na bile vesicular de pacientes com câncer colorretal: resultados preliminares. Rev bras Coloproct. 1992; 12:140-143.

24. Pinho M. Marcadores Tumorais em Câncer Colorretal. In: Rossi BM, Nakagawa WT, Ferreira FO, Aguiar Junior S, Lopes A. Câncer de Cólon, Reto e Ânus. ed. 1 $^{\text {a }}$. Edição. São Paulo. Lemar \& Tecmedd Editora, 2004, p.87-104.

25. American Society of Clinical Oncology. Clinical Practice Guidelines for the use of tumor markers in breast and colorectal cancer. J Clin Oncol. 1996; 14:2843-77.

26. Kim Y, Lee S, Park S, Jeon H, Lee W, Kin JK, Cho M, Kim M, Lim J, Kang CS, Han H. Gastorintestinal tract cancer screening using fecal carcinoembryonic antigen. Ann Clin Lab Sci. 2003; 33:32-8.

27. Shimano T, Okuda H, Monden T, Inaji H, Mori T. Usefulness of carcinoembryonic antigen measurement in feces of patients with colorectal cancer. Dis Colon Rectum. 1987; 30:607-10.

28. Goldenberg DM, Shockey RM, Primers JF. Carcinoembryonic antigen in histopathology: immunoperoxidase staining of conventional tissue sections. J Natl Cancer Inst. 1975; 57: 11-22.

29. Kim JC, Han MS, Lee HK, Kim WS, Park SK, Park KC, Bodmer WF, Rowan AF Kim OJ. Distribution of carcinoembryonic antigen and biologic behavior in colorectal carcinoma. Dis Colon Rectum.1999; 42:640-8.

30. Waisberg J, Landman G, Cha ASH, Henriques AC, Gaspar HA, Speranzini MB. Padrão da distribuição tecidual do CEA no carcinoma colo-retal: relação com o nível sérico do CEA e a classificação de Dukes. Rev bras Coloproct. 2002; 22:20-6.

31. Shimoyama T, Fukuda Y, Kusano H, Shimizu T, Takahira R, Itoh S, Watabe S, Miyashita K, Ishikawa H, Nakagoe T et al. Portal blood level of carcinoembryonic antigen (CEA) in colorectal cancer: correlation between tumor CEA content and immunohistochemical staining. Gan To Kagaku Ryoho. 1988; 15:2245-50.

32. Sunouchi K, Machinami R, Mori M, Namiki K, Hattori S, Murata Y, Tsuchiya T, Mizuno H, Tadokoro M. Clinical impact of carcinoembrionic antigen messenger ribonucleic acid expression in tumor-draining vein blood on postoperative liver metastasis in patients with colorectal carcinoma: a prospective cohort study. Dis Colon Rectum. 2003; 46:467-73.

33. Ahnen DJ, Kinoshita K, Nakane PK, Brown WR. Differential expression carcinoembryonic antigen and secretory component during colonic epithelial cell differentiation and in colonic carcinomas. Gastroenterology. 1987; 93:1330-8.

34. Salen RR, Wolf BC, Sears HF, Lavin TP, Ravikumar TS, De Coste D, Emilia JC, Meenhard H, Scholm J, Gottlieb LS, Steele GDJR. Expression of colorectal carcinoma associated antigens colonic polyps. J Surg Res. 1993; 55:249-55.

35. Tabuchi Y, Deguchi H, Saitoh Y. CEA and carbohydrate antigen 19-9 levels of peripheral and draining venous blood in colorectal cancer patients. Cancer. 1988; 62:1605-13.

36. Tokunaga N, Kijima N, Noto T, Osamura Y, Sadahiro S, Tajima T, Mitomi T. Immunohistochemical localization of carcinoembryonic antigen as a predictor of lymph node status in submucosa-invasive colorectal carcinoma. Dis Colon Rectum. 1995; 38:842-7.

Endereço para correspondência: CARLOS AUGUSTO REAL MARTINEZ

Rua Rui Barbosa, 255 apto. 32 - Vila Gilda

09.190-370 - Santo André (SP)

E-mail: caomartinez@uol.com.br 